\title{
X-RAY MICROSCOPY AND MICROANALYSIS : INTRODUCTORY SURVEY
}

\author{
V.E. Cosslett \\ Cavendish Laboratory, Cambridge, U.K.
}

Résumé - On observe un renouveau dans 1 'utilisation des rayons $X$ en microscopie dans deux cas différents : a) avec un fort pouvoir de résolution géométrique en biologie et en science des matériaux; b) sans trop s'attacher à la rêsolution géométrique en biologie, par rayonnement synchrotron.

La microanalyse par rayons $X$ continue son développement à la fois dans $1 a$ comprêhension fondamentale et dans l'instrumentation. Le choix des témoins reste le problème le plus important.

Abstract - In recent years there has been a certain revival in the use of $\mathrm{X}$-rays for microscopy. It has taken place in two quite different spheres: at low resolution for some practical purposes in biology and materials science and at higher resolution in mainly biological applications with the aid of synchrotron radiation.

Microanalysis with $X$-rays continues to develope in both fundamental understanding and in instrumentation. The major problem now seems to be to establish reliable standards.

1. Introduction

At the Cambridge conference in 1956 (1), counted ] ater as the first ICXOM meeting, the contributions were approximately equally divided between contact, projection and reflection microradiography, with small sections on microdiffraction and microanalysis. Through the succeeding meetings of the series the relative proportions have changed considerably, so that at ICXOM 9 in The Hague projection microradiography was represented by a single paper only and $\mathrm{X}$-ray optics not at all. Microanalysis had become the main interest, carried out by several other methods as well as by X-rays. At this 10 th meeting the balance has been restored to a slight extent, mainly because of the entry of synchrotron radiation as an intense source of $\mathrm{X}$-rays and its combination with the zone plate lens. A comprehensive survey of these methods of $\mathrm{X}$-ray imaging has recent1y appeared (2).

The technique of microanalysis by means of X-ray spectrometry has become so widespread that it is no longer possible to cover all of its applications here. The basic physics of it, together with the details of instrumentation on the one hand and on the other of the treatment of the recorded data, have been set out in a lengthy multi-authored treatise (3). At the same time manufacturers have made available the necessary hardware, and to some degree the associated software as well. The same may be said of the newer method of electron energy loss spectrometry. In both technologies their use has progressed faster than the laying of sound foundations: reliable standards have still to be devised and agreed upon. Surveys of these methods and related analytical techniques have recently been published by Werner (4) and by Cazaux (5).

\section{X-ray Microscopy}

Theory As a reminder of the principles of the projection technique the essentials are shown in Figure 1. A point source of $\mathrm{X}$-rays behind an object casts an image by simple geometrical projection on to a surface at a distance, so that the magnification is given by $\mathrm{M}=\mathrm{a} / \mathrm{b}$. The image may be recorded photographically, by an array of detectors or by a single detector if the source is scanned. Contrast is 
determined by variation of $\mathrm{X}$-ray absorption in the object, sharpness (and hence resolution) by Fresnel diffraction and penumbra affects. The period of exposure will depend jointly on the intensity of the radiation and on the sensitivity of the detection system.

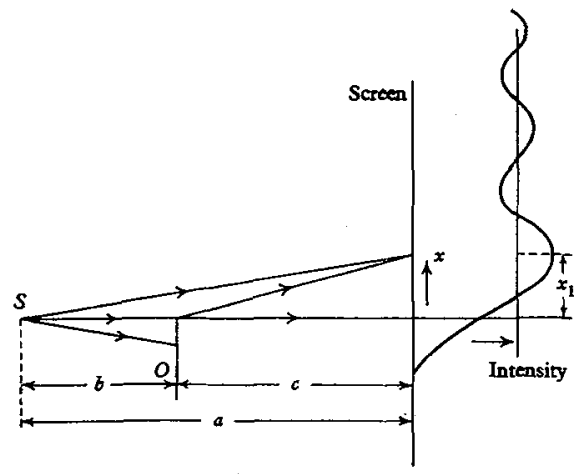

Fig. 1 - Formation of Fresnel fringes by diffraction of illumination from source $S$ at straight-edge $O$. Right: the variation of intensity across any subsequent plane of observation.

The relative influence of these factors has been discussed by Cosslett and Nixon (6) and others. The general conclusion was that projection $\mathrm{X}$-ray microscopy provides a useful extension of optical methods for specimens that are optically opaque or too thick for light microscopy. It is limited by the intensity of attainable sources of X-radiation. This intensity in turn is limited primarily by the properties of the target material: the incident electron beam may be of very high intensity, but the electrons not only deliver heat to the target but also are scattered in it. It is necessary to use a thin target in order to obtain a well defined small $\mathrm{X}$-ray source. Heat dissipation then becomes the main limiting factor in the target and hence on exposure time. Some improvement can be obtained by scanning the electron probe and some by the use of an image intensifier (7). The intensity of the electron beam can only be reduced, however, to the point where quantum statistics in the image sets a limit of its own, by the signal/noise ratio.

\section{Instrumentation}

The type of $\mathrm{X}$-ray projection microscope introduced by Cosslett and Nixon (6) has continued to be used, but there has been an increasing tendency for the technique to be adapted to a scanning EM. For moderate resolution several models are manufactured by the Wardray Company at Oxford, including one for $100-200 \mathrm{kV}$. Details of these instruments and various others made in individual laboratories are described by Ely (8). The use of an SEM for X-ray radiography has been set out by a number of authors, Brünger (9), Cazaux et a1 (10), Horn and Waltinger (11) amongst others. The experimental apparatus employed is to some extent treated in the wider survey of instrumentation in electron optics and X-ray spectroscopy by Mulvey in this Congress (12).

The use of synchrotron radiation for X-ray microscopy (Figure 2) has been explored in a number of laboratories in the United States and in Europe. The polychromatic beam may be dispersed by means of a grating at grazing incidence, and concentrated for imaging by one or more zone plates. Suitable arrangements have been described by Schmahl et al (13), Silk (14), Kirz et al (15), Sayre (16) and others. See also contributions to this Congress by Hastings and Howells (17), Schmahl et al (18), Kozlenkov and Shulgin (19) and Burge et al (20). 


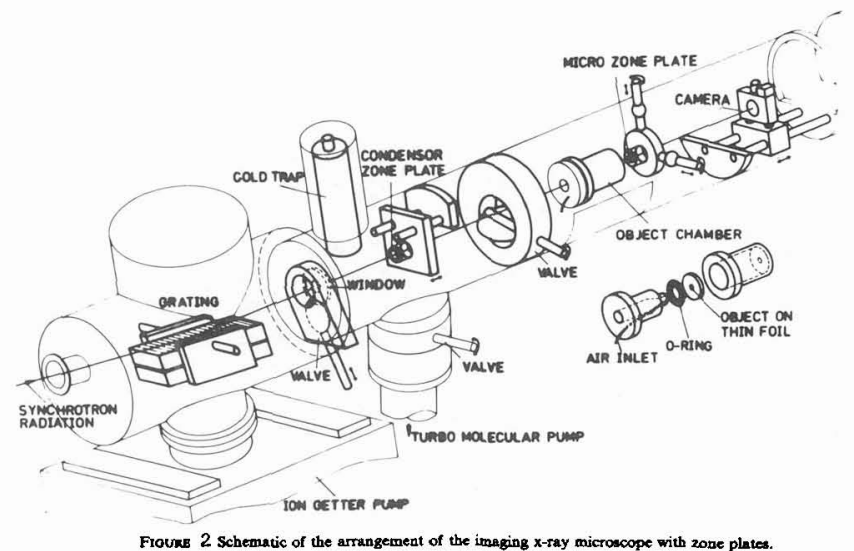

Applications $\mathrm{X}$-ray microscopy is restricted to a resolving power of the same order as that of the 1 ight microscope, $0.2-0.5 \mu \mathrm{m}$. Within these 1 imitations, however, it has found a range of applications, mostly at a poorer resolution where many of the factors mentioned above do not interfere with performance.

Some of the applications in materials science and in biology are described in "Microfocal Radiography" (8). The range of this X-ray technique is defined by Sharpe and Parish (21) as that for which the source size lies between $100 \mu m$ and "the wavelength of $X$-rays" $(0.1 \mu \mathrm{m})$. They describe the technology involved and a number of applications in engineering and reactor physics: turbine blades, integrated circuits, carbon fibres, aluminium alloys. Some metallurgical applications of the scanning techniques at a beam voltage of $30 \mathrm{kV}$ are mentioned by Cazaux et al (10).

In biology and medicine it is usually desirable to use a lower voltage, exciting softer X-rays. The wavelength range of $1-10 \mathrm{~nm}(10-100 \AA)$ is preferable, corresponding to a voltage of $\uparrow-0.1 \mathrm{kV}$, although a much higher voltage is needed to produce an $\mathrm{X}$-ray beam of adequate intensity. Biological applications in this region have been described by Schmahl et al (13), who imaged diatom and brain cells of the rat. Further investigations with synchrotron radiation are described by the same authors in a following paper in this session of the congress (abstract p.23).

For thicker biological specimens, and especially for hard tissues, more penetrating $\mathrm{X}$-rays and hence a higher voltage are required. Using apparatus operating in the range $1-30 \mathrm{kV}$ Saunders (22) has studied the microangiography of the nervous system, particularly the human cererbal cortex, after injection of contrast material. For examining histological sections he has constructed a low voltage X-ray tube for

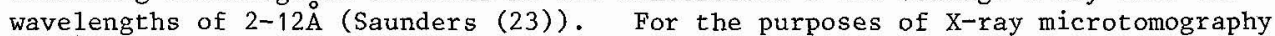
Brunger (9) uses a beam at $30 \mathrm{kV}$.

A comprehensive survey of the biological use of the projection $x$-ray microscope, at beam voitages up to $80 \mathrm{kV}$, has been given by Buckland-Wright (24). He deals with the relevant techniques, including specimen preparation and image recording, as well as their application in the study of both hard and soft tissues. For the former type of specimen a higher voltage as we11 as special preparative methods are needed. These are discussed by Fearnhead and Knight (25) in connection with the microradiography of mineralized tissues, both tooth and bone. Other applications to a wide variety of biological material, botanical as well as zoological, are described by Van Emden and Ely (26). They also discuss the effect of low doses of $\mathrm{x}$-rays on living organisms, which are sometimes radiographed in that condition in air. 


\section{Future Prospects}

The possibilities for further development of the X-ray microscope have been discussed in some detail by Stuart (27) in a long survey with many references. He sets out the relative advantages of "the 19 most significant options" in four tables. He concludes that "the electron bombarded solid/foil target source is an obvious preference unless there is a compelling requirement, such as a very high radiance or very short duration pulsed operation, which dictates otherwise". The disadvantage of a synchrotron source is the need to take an experiment to a central installation, though it has high radiance even after monochromatization. The plasma type of X-ray source is "rather costly", but is "wel1 suited to microradiography of moving objects". He describes also an unconventional single pole microfocus tube due to Pugh and West (28) in which the magnetic lens (of the Mulvey type) is combined with a standard triode electron gun; it gives a large output (up to $50 \mu \mathrm{A}$ ) at a voltage of $1-25 \mathrm{kV}$. Stuart ends by stressing the growing importance of an image processing system for interpreting the image.

\section{X-ray Microanalysis}

The technique of using $\mathrm{X}$-rays for localised analysis was pioneered by Castaing (29) and developed by Duncumb (30). It is essentially a matter of microspectrometry, relying on the variation in characteristic line emission through the periodic table. The original simple instrumentation has become increasingly complicated, as described later in this Congress by MuIvey (12). It is now part of the hardware built into the modern analytical electron microscope, although some microprobe instruments dedicated to X-ray analysis are still produced.

The technique in all its aspects, including the physical basis and the processing of data, is described in the book by Hren et al (3), of which a new edition is in the press. Its use in particular areas of science for quantitative purposes involves standard reference samples and/or a complicated system of experimenta1 corrections. In metallurgy and materials science this is sometimes a straightforward matter, but can become difficult when the sample is a thin foil (possibly of varying thickness) rather than a bulk specimen. The problem has been discussed in some detail by Goldstein and by Zaluzec in chapters 3 and 4 of reference 3 . The latter sets out a procedure for standardless analysis in both thin film and bulk samples. There is continuing discussion of the applicability and accuracy of correction methods in other sessions of this Congress.

In biology the situation is somewhat different because of the nature of tissues, so that sample preparation, specimen thickness and mode of mounting must be taken into account. These problems are described in chapter 5 of reference 3 by Hall and Gupta, and in many other publications. A very useful guide to the complexities of the application of $x$-ray microanalysis in biology is the compilation of papers from the annual SEM meetings (31). One section of it sets out the various steps in quantitative studies: "spectrum handling and background removal procedures, standards, theory of quantitation problems and sources of error". A particularly valuable paper is that by Chandler (32), which distinguishes between thick, thin and ultrathin samples, that require different treatments for quantitation.

The question of the use of standards in biological microprobe analysis is still very much a subject of contention, but at a poorer level of error $(25-10 \%)$ than in metals. It has been discussed by Roomans (33) and by Russ (34) as well as by the authors mentioned above. The recent work by Hagler et al (35) seems to promise a definitive answer to the problem. The effect of the electron beam on the specimen is a separate matter, however, which is discussed in many of these papers; it may be minimised by cryo-techniques, but not completely avsided.

\section{Conclusion}

It is tempting to make a comparison of the $x$-ray probe technique with other microanalytical methods. This is pointless in any realistic sense, however, because they differ widely in the type of application for which each is best suited. Energy loss 
spectrometry may be optimal for detecting very small aggregations of a single element, but $\mathrm{X}$-ray microanalysis is 1 ikely to be the only means of elemental analysis of a multicomponent specimen. In a broader view the principles and 1 imits of accuracy of the various methods have been discussed and tabulated by both Cazaux (5) and by Werner (4). The extent to which some technique is applicable to a particular problem can often be judged in meetings such as the present occasion.

\section{References}

(1) Cosslett, V.E. Engstróm, A. and Pattee, H.H. (Eds.) X-ray Microscopy and and Microradiography. Academic Press, New York, 1957.

(2) U1trasoft X-ray Microscopy: its Application to Biological and Physical Sciences (ed. D.R. Parsons). New York Academy of Sciences (1980).

(3) Hren, J.J., Goldstein, J.I. and Joy, D.C. Introduction to Analytical Electron Microscopy. Plenum Press, New York, 1979.

(4) Werner, H.W. in Electron Microscopy 1980, Vol.3 (eds. P. Brederoo and V.E. Cosslett), p.200.

(5) Cazaux, J., J. Microsc. Spectrosc. Electron., 7 (1982) 487.

(6) Cosslett, V.E. and Nixon, W.C. X-ray Microscopy. University Press, Cambridge, 1960.

(7) Anderton, H. and Smith, K.C.A. In Fourth International Congress on X-ray Optics and Microanalysis (ed. R. Castaing, P. Deschamps and J. Philibert). Hermann, Paris; p.426, 1965.

(8) Ely, R.V. (ed.) Microfocal Radiography. Academic Press, London, 1980.

(9) Brunger, W. Proc. 9th Internat. Cong. Elect. Microsc., Toronto I (1978) 106

(10) Cazaux, J., Mouze, D. and Perrin, J., J. App1. Phys. 53 (1982) $\overline{3} 299$.

(11) Horn, H.R.F. and Waltinger, H.G. in Electron Microscopy 1980, Vo1.1. (eds. P. Brederoo and G. Boom) p. 94.

(12) Mulvey, T. in the volume of abstracts, p. 40.

(13) Schmahl, G., Rudolph, B., Niemann, B. and Christ, 0. in Ultrasoft X-ray Microscopy. (ed. D.F. Parsons). New York Acad. Sci., 342 (1980) 368

(14) Silk, J.K. ibid, p.116

(15) Kirz, J., Burg, R. and Rarback, H. ibid. p. 135.

(16) Sayre, D. ibid. p. 387.

(17) Hastings, J.B. and Howe11s, M.R. The volume of abstracts p.21.

(18) Schmah1, G., Rudolph, D. and Niemann, B. The volume of abstracts p.23

(19) Kozlenkov, A.I. and Shulgin, A.I. The volume of abstracts, p.42

(20) Burge, R.E., Duke, P.J., Macdowe11, A., Michette, A., Miller, A., Rosser, R., Simpson, M. and West, J.B. The volume of abstracts p.25.

(21) Sharpe, R.S. and Parish, R.W. in ref. 8, chapter 2.

(22) Saunders, R.L. de C.H. in ref. 8 chapter 3.

(23) Saunders, R.L. de C.H. in "The Encyclopaedia of Microscopy and Microtechnique". (ed. P. Gray). Van Nostrand Reinhold, New York. 1973, p.603

(24) Buck:land-Wright, J.C., in ref. 8, chapter 4.

(25) Fearnhead, R.W. and Knight, D. in ref. 8, chapter 5.

(26) Van Emden, H.F. and Ely, R.V., in ref. 8, chapter 6.

(27) Stuart, P.R., in ref. 8, chapter 7.

(28) Pugh, D.J. and West, P.D. in Developments in Electron Microscopy and Analysis 1977, (ed. D.L. Misel1). Institute of Physics, Bristol and London, p.29.

(29) Castaing, R. Thesis, Paris 1951

(30) Duncumb, P. Thesis, Cambridge, 1957.

(31) Basic Methods in Biologica1 X-ray Microanalysis (ed. G.M. Roomans and J.D. Shelbourne). Scanning Electron Microscopy Inc., AMF O'Hare, 1983.

(32) Chandler, J. ref. 31 p. 1.

(33) Roomans, G.M. ref. 31 , p.251.

(34) Russ, J. ref, 31, p.261

(35) Hagler, K.H., Lopez, L.E., Flores, J.S., Lundswick, R.J. and Buja, M.L. J. Microsc. 131 (1983) 221. 